\title{
Article \\ Evaluation of Structural Behavior and Fatigue Performance of a KR-Type Rail Clip
}

\author{
Sang-Hyeok Kim ${ }^{1}$, Xiao-Jun Fang ${ }^{1}$, Yeun-Chul Park ${ }^{2}$ a and Hyoung-Bo Sim ${ }^{1, *}$ \\ 1 Department of Civil and Environmental Engineering, Incheon National University, Incheon 22012, Korea; \\ tkdgur6775@naver.com (S.-H.K.); fangxiaojun@inu.ac.kr (X.-J.F.) \\ 2 Department of Civil and Environmental Engineering, Hannam University, Daejeon 34430, Korea: \\ ycpark@hnu.kr \\ * Correspondence: hbsim@inu.ac.kr
}

Citation: Kim, S.-H.; Fang, X.-J.; Park, Y.-C.; Sim, H.-B. Evaluation of Structural Behavior and Fatigue Performance of a KR-Type Rail Clip. Appl. Sci. 2021, 11, 12074. https:// doi.org/10.3390/app112412074

Academic Editor: José A.F.O. Correia

Received: 18 November 2021

Accepted: 14 December 2021

Published: 18 December 2021

Publisher's Note: MDPI stays neutral with regard to jurisdictional claims in published maps and institutional affiliations.

Copyright: (c) 2021 by the authors. Licensee MDPI, Basel, Switzerland. This article is an open access article distributed under the terms and conditions of the Creative Commons Attribution (CC BY) license (https:// creativecommons.org/licenses/by/ $4.0 /)$.

\begin{abstract}
Rail clips are essential components of rail fastening systems that clamp the rails to sleepers. Fatigue damage of rail clips has been recently reported in railway lines. However, there has been a lack of research investigating this fatigue issue. The KR-type rail fastening system has been recently developed and used in some domestic railways. This study aimed at evaluating the structural behavior and fatigue performance of the KR-type rail clip. The assembly test performed in the laboratory showed that the stresses induced in the rail clips after tightening, particularly at the stress concentration locations, exceeded the yield stress, indicating that the rail clip could be vulnerable to fatigue cracking when combined with the stress range during repeated trainloads. The finite element analysis results, which revealed a good correlation with the experiments, were used to evaluate the fatigue performance of the rail clip by adopting the modified Goodman fatigue criteria. The fatigue evaluation results indicated that when the vertical rail displacement during train operation exceeded $2 \mathrm{~mm}$, the rail clips could potentially suffer from fatigue failure.
\end{abstract}

Keywords: rail fastening system; rail clip; fatigue; finite element analysis

\section{Introduction}

A rail fastening system clamps rails to railway sleepers or railway ties and is the main component of a railway track that delivers the trainload to the substructure. A rail clip (or rail clamp) is an essential part of a rail fastening system and provides a clamping force linking the rail and sleeper together to prevent tipping and the longitudinal and transverse displacement of the rail.

A rail clip can be vulnerable to fatigue cracks because it is acted upon by high initial stresses during the assembly process and fluctuating stresses from repeated trainloads. Fatigue damages of rail clips have been reported in South Korea and other countries (see Figure 1 as an example) [1,2]. If fatigue damage of multiple rail clips occurs simultaneously in a railway track, potential train derailment could occur, placing passenger comfort and riding safety at risk.

Although the assessment of fatigue performance of rail clips plays such a vital role in terms of ensuring safety, limited research has been performed to investigate the exact cause of any fatigue damage on rail clips in the field. Past research has mainly focused on investigating the mechanical behavior and structural dynamics of rail fastening systems by employing numerical analyses, including understanding the interaction between track components [3-5]. There is a dearth of research evaluating the fatigue life of rail clips. A method to analyze the stress-based fatigue reliability of a rail clip under random train loading was also developed. The sensitivity analysis showed that the equivalent stress range had the largest influence on the fatigue reliability index. However, the fatigue evaluation technique proposed by the authors was based on crack propagation under the assumption of a small initial crack. The fatigue crack initiation life was not considered [6]. 


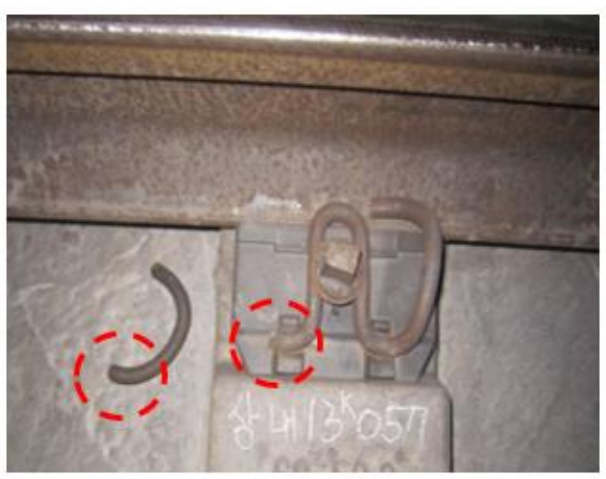

Figure 1. Damaged rail clip.

Failure analysis of fatigue cracking was performed in the tension clamp SKL15 of the rail fastening system DFF-300. The fatigue performance of the tension clamps was determined based on both field measurements and finite element analyses (FEA). The authors evaluated the fatigue performance of the tension clamps, considering both the initial stress from the assembly process and the stress amplitude from repeated trainload, using the modified Goodman and Gerber diagrams to analyze the possibility of fatigue cracking [1].

The KR-type rail fastening system has been developed in South Korea and used in some domestic railways. Figure 2 depicts the main components and assembled configuration of this rail fastening system. The fatigue performance of the rail clip has been assessed by conducting a simple fatigue test; however, a thorough fatigue performance investigation has not been conducted yet. In this study, both the structural behavior and fatigue performance of the KR-type rail fastening system were evaluated through laboratory tests and FEA. A laboratory assembly test was first performed to investigate the system's global response and local deformation pattern in an effort to identify potential fatigue vulnerabilities in the presence of stress concentration on the rail clip. The natural frequencies of the rail clip were also determined by performing a modal test in the laboratory. FEA was then conducted to supplement and compare the output with the experimental results. In FEA, the assembly process and the vertical rail movement of a train passage were simulated in two steps to capture the stress states from which one could assess any potential fatigue failure of the rail clip by using the modified Goodman diagram.

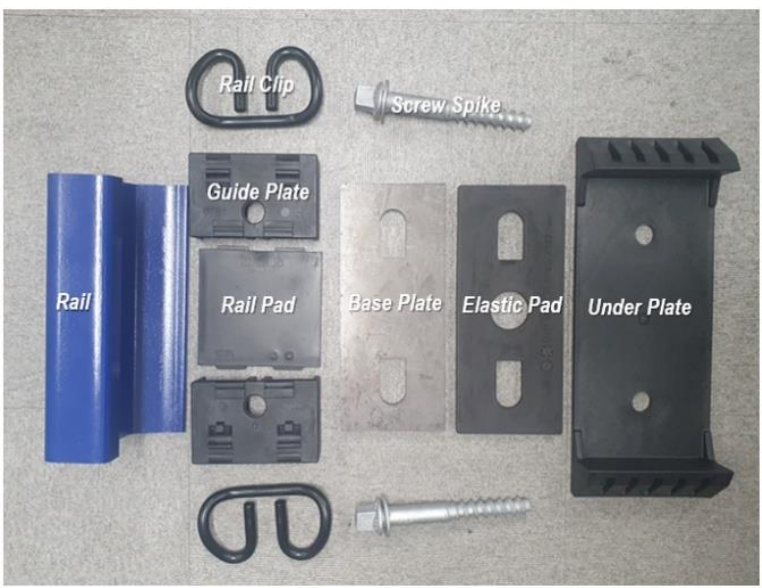

(a)

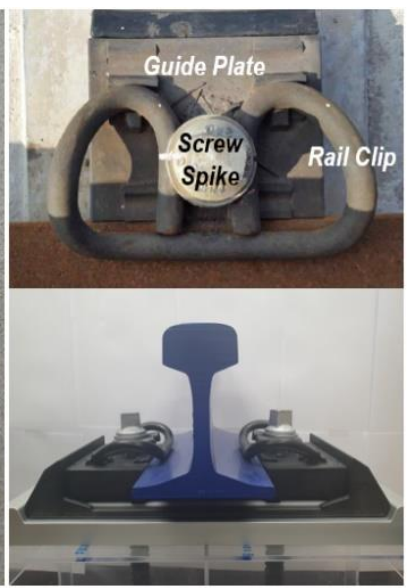

(b)

Figure 2. The KR-type rail fastening system: (a) components; (b) assembled configuration. 


\section{Laboratory Measurements}

\subsection{Tensile Coupon Test}

Tensile coupon tests with three test specimens were performed to measure the mechanical properties of SPS9A spring steel used in KR-type rail clips using the Korean Industrial Standards [7]. The results of the tensile test are shown in Table 1. Figure 3 shows the stress-strain curve of the material. The modulus of elasticity was approximately 205 GPa. The average values of $0.2 \%$ offset yield stress, tensile strength, and elongation were $1377 \mathrm{MPa}, 1509 \mathrm{MPa}$, and $9.6 \%$, respectively.

Table 1. Steel mechanical properties.

\begin{tabular}{cccc}
\hline $\begin{array}{c}\text { Specimen } \\
\text { No. }\end{array}$ & $\begin{array}{c}\text { Yield Stress } \\
\text { (MPa) }\end{array}$ & $\begin{array}{c}\text { Tensile Strength } \\
\text { (MPa) }\end{array}$ & $\begin{array}{c}\text { Elongation at Failure } \\
\text { (\%) }\end{array}$ \\
\hline 1 & 1383 & 1517 & 11.0 \\
2 & 1379 & 1514 & 9.3 \\
3 & 1368 & 1497 & 8.5 \\
\hline
\end{tabular}

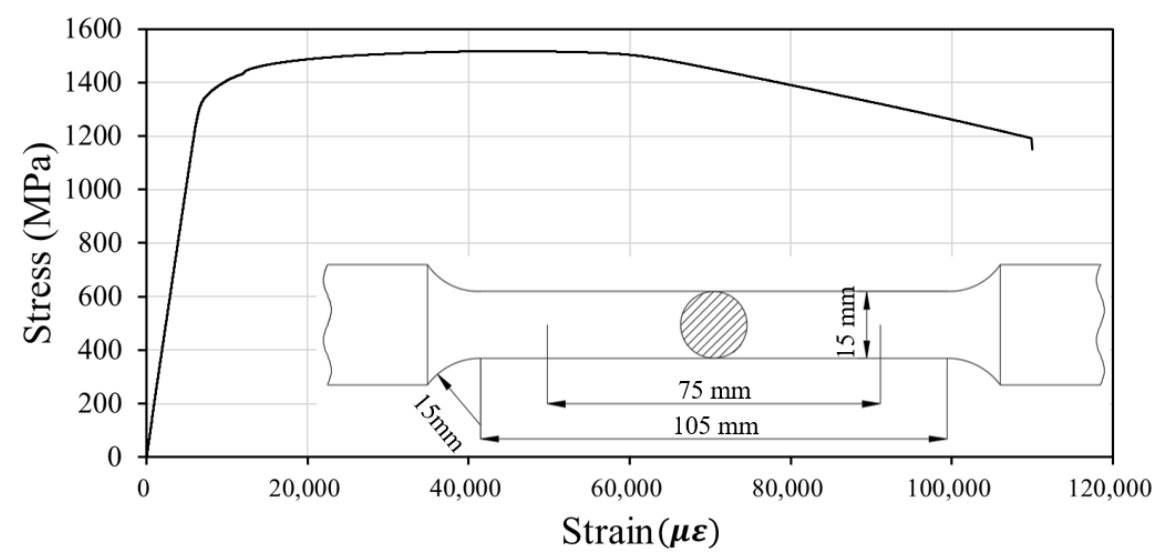

Figure 3. Stress versus strain curve (for coupon specimen 1).

\subsection{Assembly Test}

An assembly test was performed in the laboratory to evaluate the structural behavior of the rail clip during fastening, as shown in Figure 4. A torque of $250 \pm 25 \mathrm{~N} \cdot \mathrm{m}$ was applied to the screw spike using a torque wrench until the central part of the clip came in contact with the guide plate. A combination of displacement transducers and rosette strain gauges was placed in specific locations of the clip to measure its global and local responses during the fastening procedure. The strain gauges were installed at highly curved locations where high stress concentration was expected.

Figure 5 illustrates the global response of the clip. The vertical axis represents the torque applied to the screw spike for fastening the clip to the rail, while the horizontal axis represents the average vertical displacement at the central end of the clip, as shown in Figure 5. Elastic behavior was exhibited until the clip came in contact with the guide plate, at which point the torque applied was approximately $230 \mathrm{~N} \cdot \mathrm{m}$ at the vertical displacement of $11.4 \mathrm{~mm}$. From the rosette strain gauge measurements during the fastening process, the maximum principal strains at three locations (i.e., R1, R2, and R3 in Figure 6) were calculated and plotted as shown in Figure 6. During the unloading procedure, the strains upon complete removal of torque were measured. The presence of some residual strains indicated that the strains during tightening exceeded the yield strains, particularly at locations R2 and R3. It should be noted that such local plastic behavior exhibited by the clip during fastening would have been more obvious if the strain gauges were placed at locations with more severe stress concentrations. 

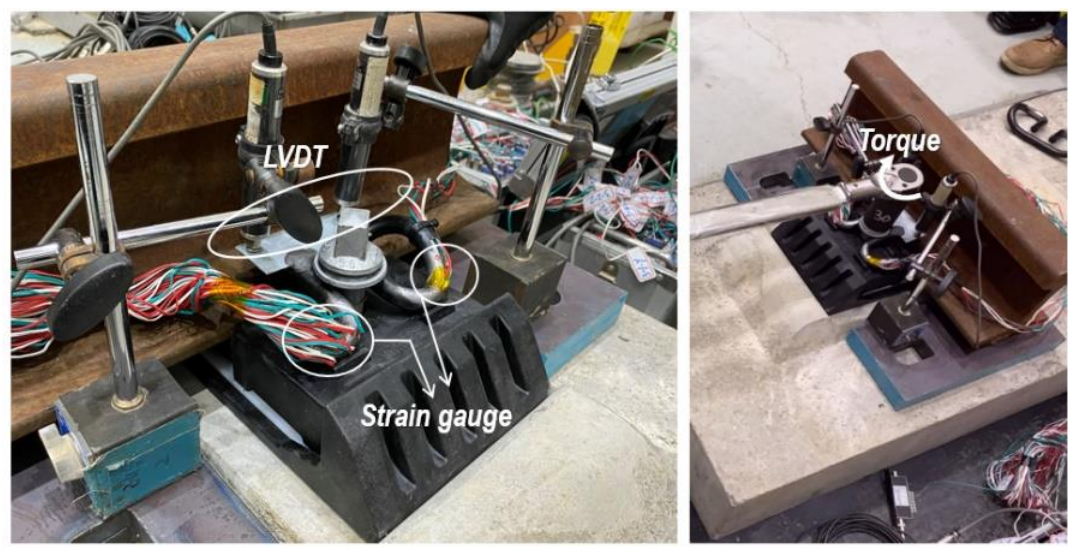

Figure 4. Assembly test setup.

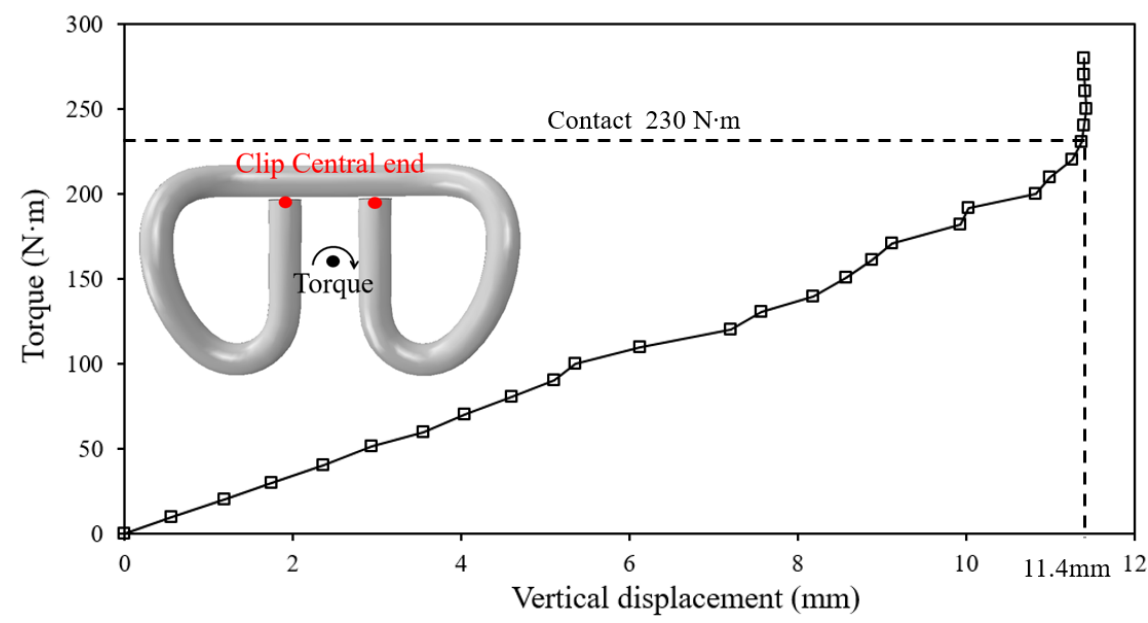

Figure 5. Global response of the clip (torque vs. vertical displacement).

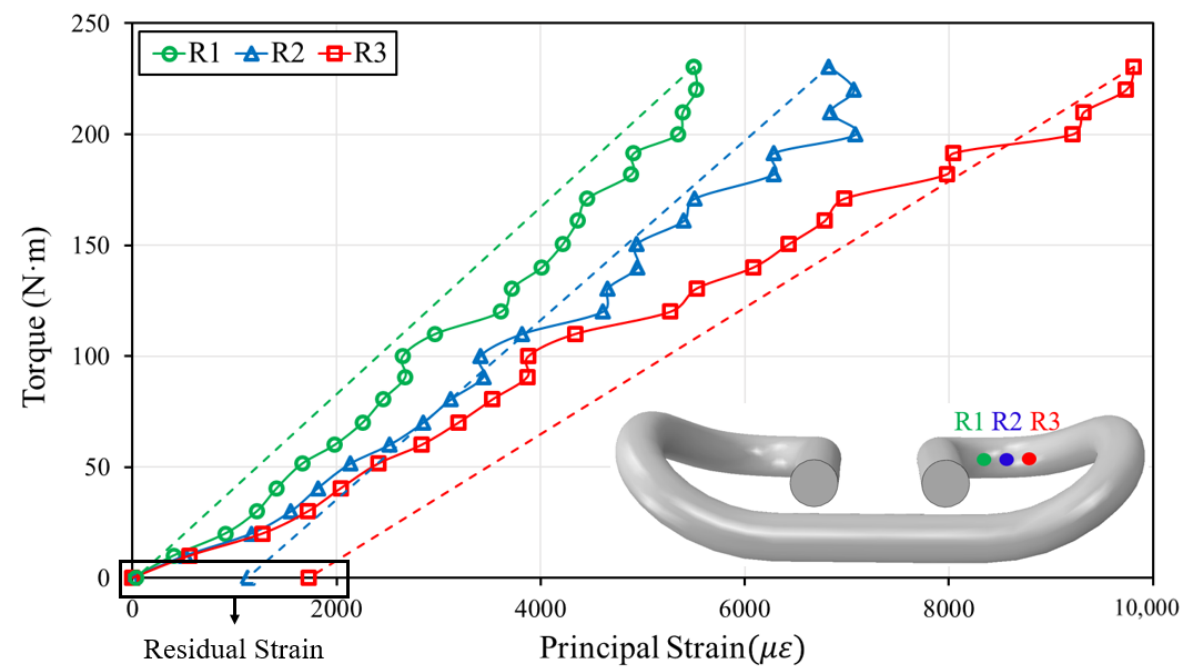

Figure 6. Strain measurements (torque vs. principal strains).

After the assembly of the rail fastening system was completed, a modal test was performed to identify the natural frequencies of the clips using an impact hammer and an accelerometer. Figure 7 shows the configuration of the modal test setup. The accelerometer was installed at one side of the rail clip arm, and an impact hammer was used to strike the other side (see Figure 7). A total of three tests were performed. The average values of the 
first, second, and third natural frequencies through modal analysis were $871 \mathrm{~Hz}, 1025 \mathrm{~Hz}$, and $1272 \mathrm{~Hz}$, respectively.

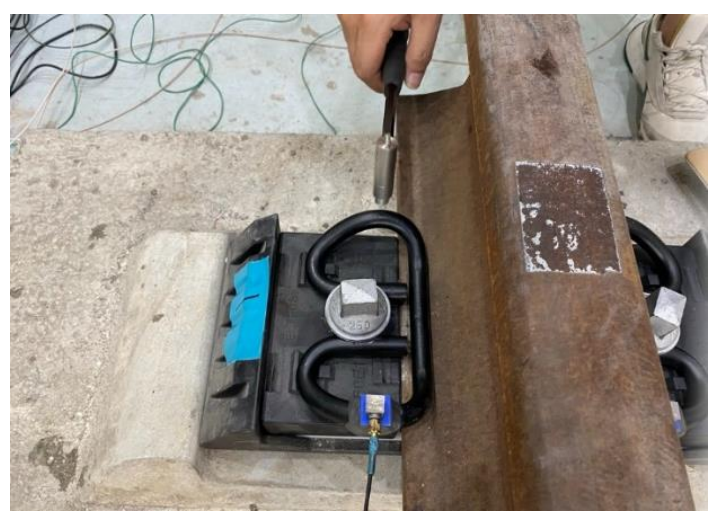

Figure 7. Modal test setup.

\section{Finite Element Analysis}

\subsection{Modeling Details}

In addition to the laboratory testing, FEA was performed to study the structural behavior of the rail clip, including the stress fields acting on it. Due to the complex shape of the clip, 3D scanning of the clip was performed, and the scanned shape of the clip was imported into the FEA software Abaqus [8]. The 3D solid elements (referred to as C3D8R in Abaqus) and the inelastic material properties were applied to the model. The trilinear input material model of the analysis (shown in Figure 8) was assumed based on the tensile coupon tests outlined in Section 2.1. A Poisson's ratio of 0.29 and an elastic modulus of 205 GPa were assigned. To account for the stiffness of the elastic pad underneath the rail, spring elements with a stiffness of $12,500 \mathrm{~N} / \mathrm{mm}$ were added in the vertical direction at the clip-to-rail contact location. Total number of nodes, elements and degrees of freedom of the model were 15,867,12,880 and 47,601, respectively. Minimum size of an element was $2.2 \mathrm{~mm}$ and aspect ratio was limited to 1:4. The size of the element was determined based on a mesh convergence test.

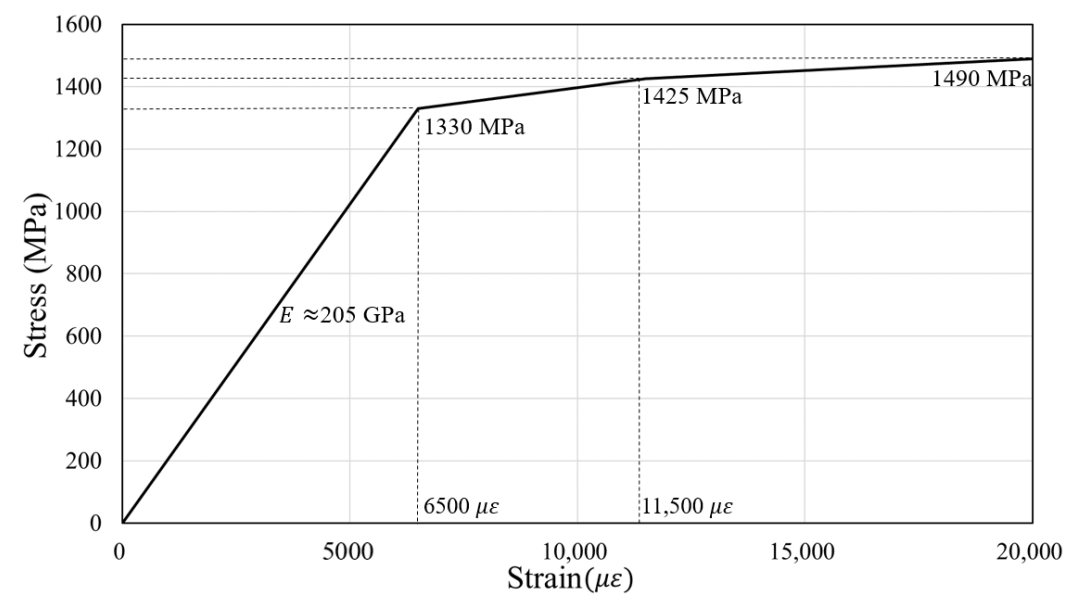

Figure 8. Properties of the input material.

Two loading steps were applied to simulate the installation of the rail clip and vertical displacement during train operation, as shown in Figure 9. In step 1, the top surface of the central part of the clip was tied to the center point, and a vertical displacement was applied to this center point, simulating the tightening of the screw spike. The level of displacement applied in step 1 was $11.4 \mathrm{~mm}$, based on the laboratory measurements in Figure 5. In step 2 , vertical displacements of $1 \mathrm{~mm}, 2 \mathrm{~mm}$, and $3 \mathrm{~mm}$ were applied to the clip-to-rail contact 
location to simulate the movement of the clip during train operation. In step 1, modal analysis was also performed to evaluate the natural frequencies and the corresponding mode shapes.

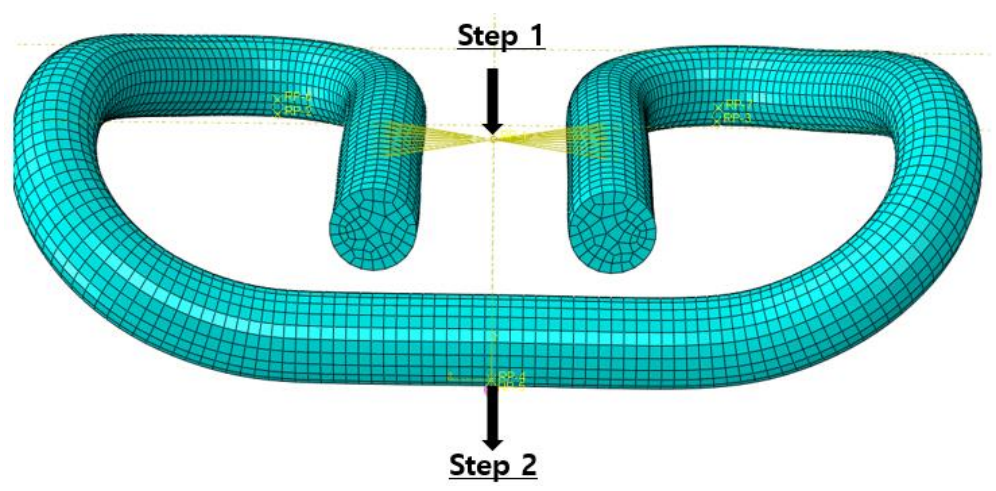

Figure 9. Loading steps of finite element analysis.

\subsection{Results of Analysis}

The results obtained through FEA were first verified by comparing it with the experimental results. Figure 10 provides a comparison of the maximum principal strains between the strain measurements in the laboratory assembly test and the FEA results in step 1. Figure 10a-c show a comparison of the strains along the circumference at the three different cross sections of the rail clip, which are denoted by "Left", "Center", and "Right" in Figure 10d. The boundary position marked in Figure 10b is near the region contacted between the rail clip and the guide plate. The plot of the strains obtained from the analysis is shown through the black solid lines. The red dots are the strains measured from the assembly test. A comparison of strains revealed a good correlation with an average error of about $14 \%$. Table 2 shows the natural frequencies and their associated mode shapes obtained through the frequency analysis performed in Abaqus. The natural frequencies are also compared with the measured ones from the laboratory modal test in this table. The comparison of natural frequencies indicated a good correlation, with an error of about $15 \%$.

The global response in the two loading steps is plotted in Figure 11. The vertical axis represents the vertical force applied to the torque location while the horizontal axis represents the vertical displacement at the clip end in step 1. As shown in Figure 11, although the global response typically exhibits elastic behavior, a slight plastic behavior is also observed as the applied force approaches closer to the tightened end (i.e., the initial straight line gets inclined a little toward the tightened end).

Figure 12 depicts the contours of the maximum principal stress. While Figure 12a shows the contours after the completion of step 1 (which simulates the assembly process), Figure $12 \mathrm{~b}$ shows the contours for steps $1-2$ (which simulates the vertical movement of the rail clip from the train passage) (i.e., the contours in Figure $12 \mathrm{~b}$ represent the stress range). It should be noted that the stresses were relieved due to the train passage, because the downward vertical movement of the rail reduced the clamping force of the rail clip. Since both mean stress (or maximum stress) and stress amplitude affect fatigue performance, the locations where the maximum stress or the stress amplitude were high can potentially represent fatigue crack initiation. These locations were identified in the red color of the stress contours in Figure 12. 


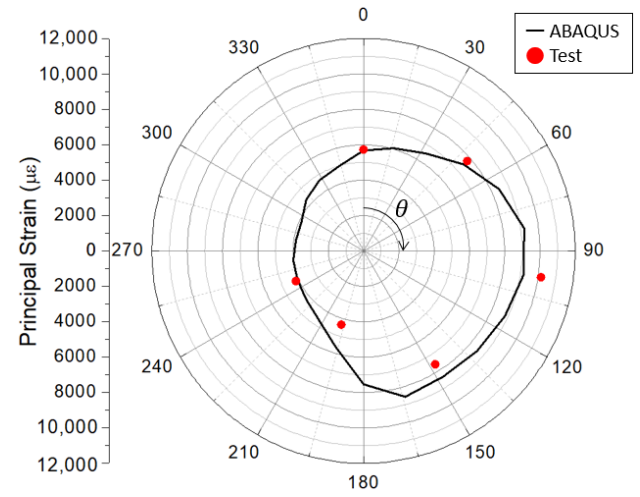

(a)

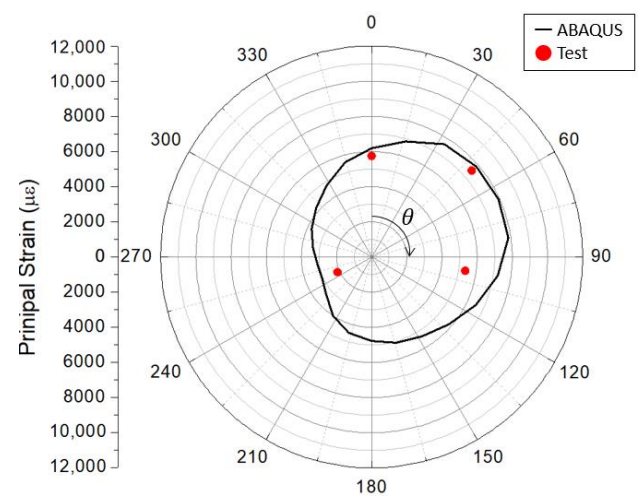

(c)

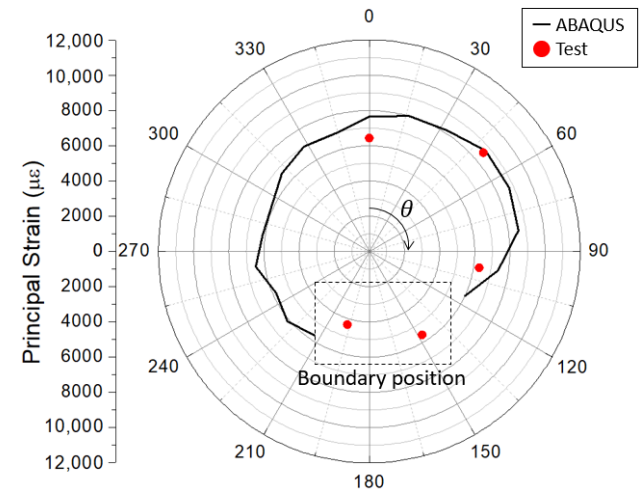

(b)

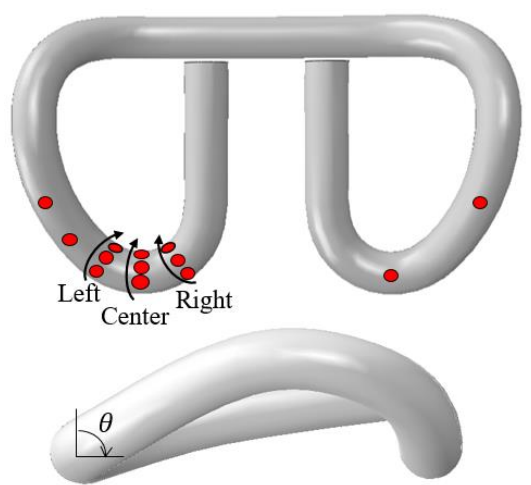

(d)

Figure 10. Comparison of test results and those obtained through Abaqus (maximum principal strains) in step 1: (a) left section; (b) center section; (c) right section; (d) strain gauge locations.

Table 2. Comparison of natural frequencies (test vs. Abaqus).

\begin{tabular}{|c|c|c|c|c|}
\hline Mode & $\begin{array}{l}\text { Test } \\
(\mathrm{Hz})\end{array}$ & $\begin{array}{c}\text { Abaqus } \\
\text { (Hz) }\end{array}$ & $\begin{array}{c}\text { Error } \\
(\%)\end{array}$ & Mode Shape \\
\hline $1 \mathrm{st}$ & 871 & 999 & 14.7 & \\
\hline 2nd & 1025 & 1181 & 15.2 & \\
\hline $3 \mathrm{rd}$ & 1272 & 1478 & 16.2 & \\
\hline
\end{tabular}




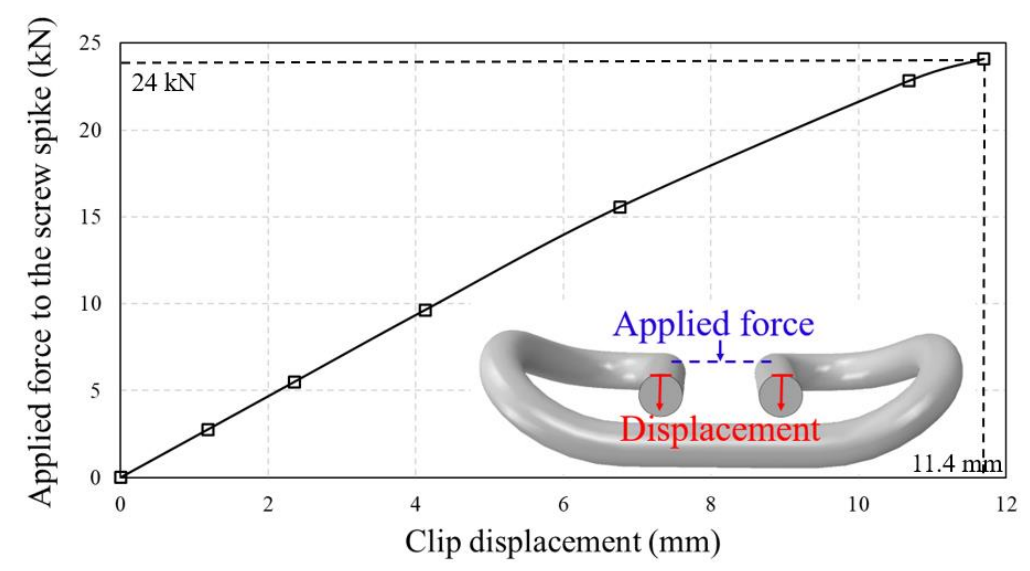

Figure 11. Global response of the clip (force vs. displacement).

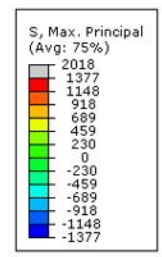

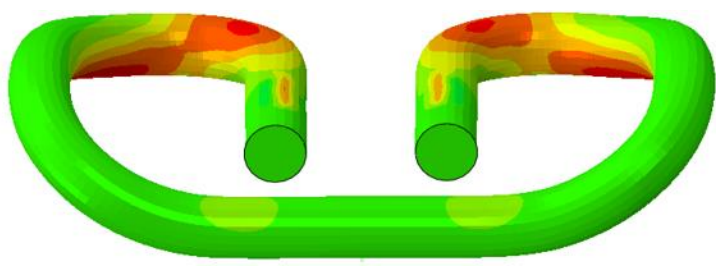

(a)
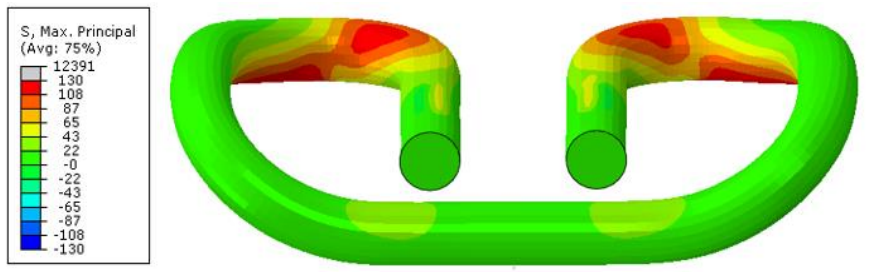

(b)

Figure 12. Principal stress contours: (a) step 1, (b) stress range between steps 1 and 2 for displacement range of $2 \mathrm{~mm}$.

A fatigue test was conducted at Hybrid Structural Testing Center at Myongji University using a $100 \mathrm{kN}$ dynamic actuator with the loading frequency of $5 \mathrm{~Hz}$. The rail clips were tested for various constant displacement ranges from $0.8 \mathrm{~mm}$ to $4 \mathrm{~mm}$. Irrespective of the constant displacement ranges, KR-type rail clips have revealed that fatigue cracks occur at two different locations and propagate along different paths. Figure 13 shows the failure modes (failure modes 1 and 2) from the fatigue test, which were compared with the ones obtained through FEA. From Figure 13, it can be observed that the crack initiation points identified from the fatigue tests are similar to the stress concentration locations obtained through FEA.

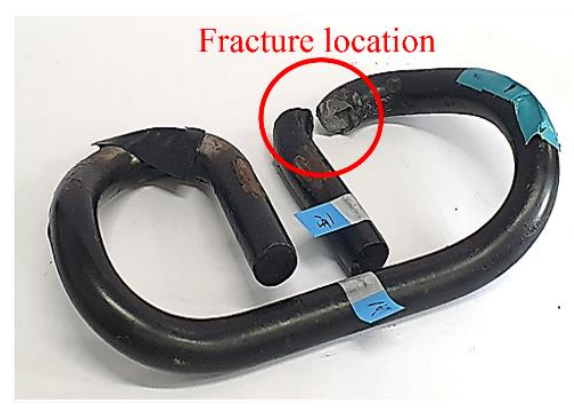

(a)

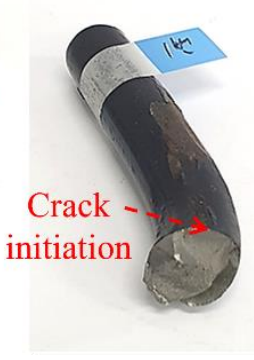

igure 13. Fatigue failure modes: (a) mode $1 ;(\mathbf{b})$ mode 2.
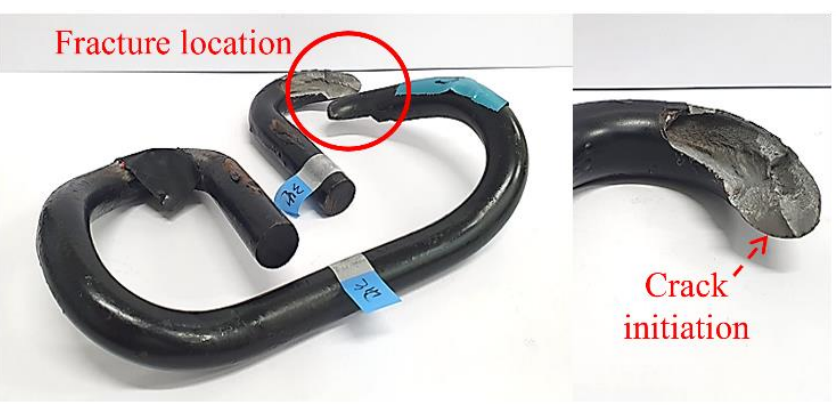

(b)

\section{Fatigue Performance Evaluation}

The rail clip is a structure designed in such a way that the initial stress generated during the assembly process is relieved by the trainload during train operation. Stress ranges, due to the relieved stress and high initial stress, render the rail clip susceptible to fatigue cracking. The possibility of fatigue failure can be evaluated by the equation based on the fatigue criteria, which is given as follows [9]: 


$$
\text { Modified Goodman equation : } \frac{\sigma_{m}}{S_{u}}+\frac{\sigma_{a}}{S_{e}} \leq 1
$$

where $\sigma_{m}$ and $\sigma_{a}$ are the mean stress and stress amplitudes, respectively. $S_{u}$ and $S_{e}$ are the tensile strength and endurance limit of the material, respectively. The endurance limit generally lies within the range of $35-60 \%$ of the tensile strength of the material $[10,11]$. The endurance limit of $528 \mathrm{MPa}$ (35\% of the tensile strength) was conservatively selected. From Equation (1), the fatigue failure (through a planar graph represented by the stress amplitude and average stress) can be determined. The straight line obtained through the fatigue equation, shown in Figure 14, is related to the fatigue limit. If the actual stress amplitude is greater than the fatigue limit, fatigue cracking can occur. The fatigue performance for the two possible failure modes was determined using this approach.

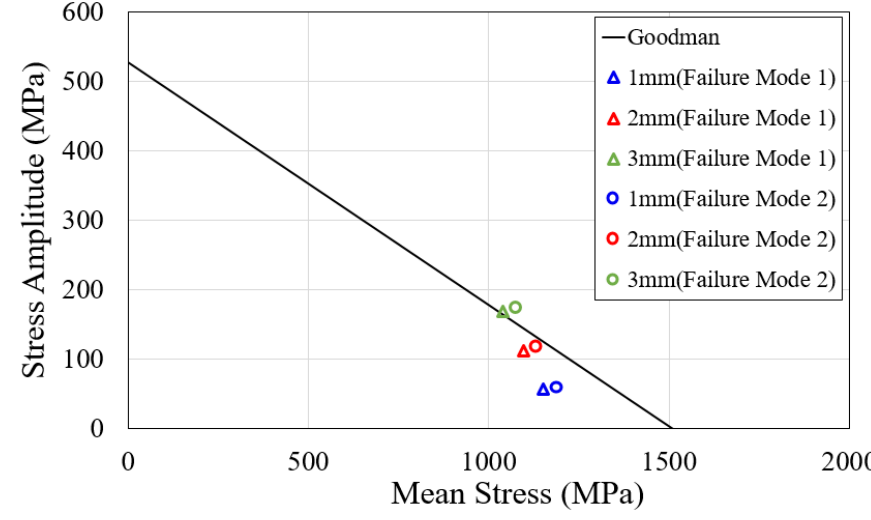

(a)

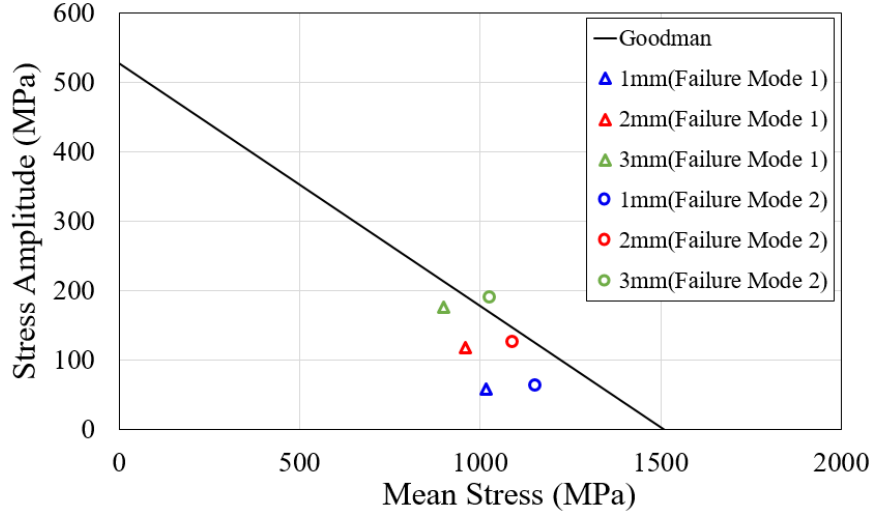

(b)

Figure 14. Fatigue performance evaluation of the rail clips: (a) step 1; (b) steps 1-2.

From Equation (1), the fatigue limit can be determined by both the mean stress and the stress amplitude, and these stresses vary with the maximum stress. Thus, the maximum stress and maximum stress amplitude are two key factors that determine the fatigue limit. The maximum stress and maximum stress amplitude can be determined from step 1 and the difference between steps 1 and 2 (i.e., steps 1-2) during analysis, respectively. The maximum principal stresses for the two failure modes for step 1 and steps 1-2 are tabulated in Table 3. Vertical displacements of 1,2, and $3 \mathrm{~mm}$ are also considered.

Table 3. Stress conditions for fatigue performance evaluation.

\begin{tabular}{|c|c|c|c|c|c|c|c|}
\hline & & \multicolumn{3}{|c|}{ Failure Mode 1} & \multicolumn{3}{|c|}{ Failure Mode 2} \\
\hline \multicolumn{2}{|c|}{ Vertical Displacement } & $1 \mathrm{~mm}$ & $2 \mathrm{~mm}$ & $3 \mathrm{~mm}$ & $1 \mathrm{~mm}$ & $2 \mathrm{~mm}$ & $3 \mathrm{~mm}$ \\
\hline \multirow{4}{*}{$\begin{array}{l}\text { Maximum principal stress } \\
\text { for step } 1\end{array}$} & $\begin{array}{c}\text { Maximum stress (step } 1) \\
\sigma_{\max }(\mathrm{MPa})\end{array}$ & & 1208 & & & 1250 & \\
\hline & $\begin{array}{c}\text { Minimum stress (step } 2) \\
\sigma_{\min }(\mathrm{MPa})\end{array}$ & 1096 & 983 & 870 & 1135 & 1018 & 902 \\
\hline & $\begin{array}{l}\text { Mean stress } \\
\sigma_{m}(\mathrm{MPa})\end{array}$ & 1152 & 1095 & 1039 & 1192 & 1134 & 1076 \\
\hline & $\begin{array}{c}\text { Stress amplitude } \\
\sigma_{a}(\mathrm{MPa})\end{array}$ & 56 & 112 & 169 & 58 & 116 & 174 \\
\hline \multirow{4}{*}{$\begin{array}{l}\text { Maximum principal stress } \\
\text { for steps } 1-2\end{array}$} & $\begin{array}{c}\text { Maximum stress (step } 1) \\
\sigma_{\max }(\mathrm{MPa})\end{array}$ & & 1076 & & & 1217 & \\
\hline & $\begin{array}{c}\text { Minimum stress (step } 2) \\
\sigma_{\min }(\mathrm{MPa})\end{array}$ & 959 & 841 & 723 & 1092 & 965 & 839 \\
\hline & $\begin{array}{c}\text { Mean stress } \\
\sigma_{m}(\mathrm{MPa})\end{array}$ & 1017 & 956 & 900 & 1155 & 1091 & 1028 \\
\hline & $\begin{array}{l}\text { Stress amplitude } \\
\sigma_{a}(\mathrm{MPa})\end{array}$ & 59 & 117 & 176 & 63 & 126 & 189 \\
\hline
\end{tabular}


Figure 14 shows the fatigue performance evaluation of the rail clips for various vertical displacements of the rail. When the vertical displacement was $2 \mathrm{~mm}$ or larger, the stress amplitudes either approached or were greater than the fatigue limit. However, when the vertical displacement was $1 \mathrm{~mm}$, the stress amplitude was far below the fatigue limit, indicating that if the rail was installed at the site where the vertical displacement was $2 \mathrm{~mm}$ or larger, fatigue failure could potentially occur. It should be noted that the measured peak strain after assembly was higher than the analysis result. Thus, actual mean stress could be higher resulting lower fatigue performance.

\section{Conclusions}

In this study, the structural behavior of the KR-type rail clip was analyzed by conducting laboratory tests. The fatigue performance of the rail clip was also evaluated through FEA. The following conclusions can be drawn:

1. During assembly testing, a high level of initial tensile stress, exceeding the yield stress, acted in some locations where a high stress concentration was expected. Such high initial stress, when combined with the stress range during train passage, indicates that the rail clip could be vulnerable to fatigue cracking.

2. The fatigue test results of the KR-type rail clips showed two different failure modes. The crack initiation points observed from the test matched well with the maximum principal stress concentration segments obtained through FEA. The comparison of natural frequencies of the clips, between the test results and those obtained through FEA, also showed a good correlation.

3. The results obtained through FEA were used to evaluate the fatigue performance of the KR-type rail clip by adopting the modified Goodman fatigue criteria. The results indicated that when the rail vertical displacement due to train operation was $2 \mathrm{~mm}$ or less, it was unlikely for fatigue failure to occur.

4. The evaluation of fatigue performance in this study was based on the initial stress and alternating stress acting on the rail clip. Further research, to analyze the impact of other parameters, including the residual stress and decarburized layer of the rail clip, might be required to obtain more conclusive and accurate fatigue evaluation results.

Author Contributions: Conceptualization-S.-H.K.; methodology-H.-B.S. and Y.-C.P.; validationH.-B.S. and Y.-C.P.; formal analysis-S.-H.K.; investigation-S.-H.K. and X.-J.F.; resources-H.-B.S.; writing (original draft preparation)-S.-H.K.; writing (review and editing)-H.-B.S., Y.-C.P. and X.-J.F.; visualization-S.-H.K. and X.-J.F.; supervision-H.-B.S.; project administration-H.-B.S.; funding acquisition-H.-B.S. and Y.-C.P. All authors have read and agreed to the published version of the manuscript.

Funding: This work has been supported by the National Research Foundation of Korea (NRF). Grant funded by the Korea government (MSIT) (No. 2020R1A4A4079299).

Institutional Review Board Statement: Not applicable.

Informed Consent Statement: Not applicable.

Data Availability Statement: Not applicable.

Acknowledgments: The photograph of fatigue failure was provided by the Hybrid Structural Testing Center at Myongji University.

Conflicts of Interest: The authors declare no conflict of interest.

\section{References}

1. Park, Y.C.; An, C.B.; Sim, H.B.; Kim, M.C.; Hong, J.K. Failure analysis of fatigue cracking in the tension clamp of a rail fastening system. Int. J. Steel Struct. 2019, 19, 1570-1577. [CrossRef]

2. Schijve, J. Fatigue of Structures and Materials, 2nd ed.; Springer: Dordrecht, The Netherlands, 2009.

3. Carrascal, I.A.; Casado, J.A.; Polanco, J.A.; Gutiérrez-Solana, F. Dynamic behavior of railway fastening setting pads. J. Eng. Fail. Anal. 2007, 14, 364-373. [CrossRef] 
4. $\quad$ Romero, M.J.G.; Edwards, J.R.; Barkan, C.P.; Wilson, B.; Mediavilla, J. Advancements in Fastening System Design for North American Concrete Crossties in Heavy-Haul Service. In Proceedings of the AREMA 2010 Annual Conference \& Exposition, Urbana, IL, USA, 31 August 2010.

5. Konstantinos, G. Secondary Stiffness of Fastening's Clip: Influence on the Behavior of the Railway Track Panel. In Proceedings of the Transport Research Arena, Paris, France, 15 April 2014.

6. Mohammadzadeh, S.; Ahadi, S.; Nouri, M. Stress-based fatigue reliability analysis of the rail fastening spring clip under traffic loads. Lat. Am. J. Solids Struct. 2014, 11, 993-1011. [CrossRef]

7. Korean Agency for Technology and Standards. KS B 0802: Method of Tensile Test for Metallic Materials; Korean Agency for Technology and Standards: Sejong-si, Korea, 2001. (In Korean)

8. Dassault, S. ABAQUS; Version 6.14-1; ABAQUS Inc.: Palo Alto, CA, USA, 2014.

9. Budynas, R.G. Advanced Strength and Applied Stress Analysis, 2nd ed.; McGraw Hill: New York, NY, USA, 1999 ; pp. $534-537$.

10. Bannantine, J.A.; Comer, J.J.; Handrock, J.L. Fundamentals of Metal Fatigue Analysis; Prentice Hall: Englewood Cliffs, NJ, USA, 1990.

11. Park, Y.C.; An, C.B.; Kim, M.C.; Sim, H.B. Effect of the depth of decarburized layer in SKL15 tension clamp on fatigue Strength. Appl. Sci. 2021, 11, 3841. [CrossRef] 